\title{
Comparing watershed soil erosion of Taiwan and Thailand
}

\author{
Yi-Hsin Liu ${ }^{1}$, Kieu Anh Nguyen ${ }^{1}$, Walter Chen ${ }^{1, *}$, Jatuwat Wattanasetpong ${ }^{2}$, and Uma Seeboonruang ${ }^{2}$ \\ ${ }^{1}$ Department of Civil Engineering, National Taipei University of Technology, Taipei, Taiwan \\ ${ }^{2}$ Department of Civil Engineering, King Mongkut's Institute of Technology Ladkrabang, Bangkok, Thailand
}

\begin{abstract}
Tropical watersheds in Taiwan and Thailand face the same severe soil erosion problem that is increasing at an alarming rate. In order to evaluate the severity of soil erosion, we quantitatively investigate the issue using a common soil erosion model (Universal Soil Loss Equation, USLE) on the Shihmen reservoir watershed of Taiwan and the Lam Phra Ploeng basin of Thailand, and compare their respective erosion factors. The results show an interesting contrast between the two watersheds. Some of the factors (rainfall factor, slope-steepness factor) are higher in the Shihmen reservoir watershed, while others (soil erodibility factor, cover and management factor) are higher in the Lam Phra Ploeng basin. The net result is that these factors cancel each other out, and the amount of soil erosion of the two watersheds are very similar at $68.03 \mathrm{t} / \mathrm{ha} / \mathrm{yr}$ and $67.57 \mathrm{t} / \mathrm{ha} / \mathrm{yr}$, respectively.
\end{abstract}

\section{Introduction}

In contrast to cold regions where soil formation is slow, the tropical Taiwan and Thailand both have prevailing weathering environments and thick deposits of soils. As a result, soil erosion is taking place at an alarming rate. With the loss of precious topsoil, agricultural productivity is negatively impacted (in the case of Thailand) and reliable drinking water supply is jeopardized (in the case of Taiwan). To better identify and understand the different contributing factors of soil erosion in typical watersheds of Taiwan and Thailand, we continue a previous study [1] in this paper to quantitatively compare the characteristics of the watersheds of Taiwan and Thailand and their respective erosion factors.

\section{Materials and methods}

One watershed was selected from each country and the major characteristics of the watersheds are summarized in Table 1. In Taiwan, the Shihmen reservoir watershed is selected as the study area. It is geographically located from $121^{\circ} 10^{\prime} 15^{\prime \prime} \mathrm{E}$ to $121^{\circ} 23^{\prime} 10^{\prime \prime} \mathrm{E}$ longitude and from $24^{\circ} 25^{\prime} 45^{\prime \prime} \mathrm{N}$ to $24^{\circ} 51^{\prime} 20^{\prime \prime} \mathrm{N}$ latitude. The Shihmen reservoir is the third largest reservoir in Taiwan and has an effective storage capacity of $207,000,000 \mathrm{~m}^{3}$ [2]. The reservoir was built in 1956 . The catchment area to which the reservoir belongs is 75953 ha. The general topography of the watershed is steep and rugged. Because the reservoir supplies drinking water to major cities in northern Taiwan, most of the watershed was declared protected area from farming and cultivation activities. However, suspended sediments and mudflow are often caused by torrential rains in the monsoon seasons. The reservoir faces a crisis to continuously supply safe drink water to the public.

On the other hand, the Lam Phra Ploeng basin is chosen as the study area of Thailand. It is located between latitude $14^{\circ} 18^{\prime} 30^{\prime \prime}$ and $14^{\circ} 38^{\prime} 30^{\prime \prime}$ north and longitude $101^{\circ} 30^{\prime} 00^{\prime \prime}$ and 101 54'00" east. The Lam Phra Ploeng dam was constructed in 1963 for a basin mostly dedicated for agricultural uses nowadays. The size of the Lam Phra Ploeng basin is 81745 ha, slightly bigger than the Shihmen reservoir watershed. The average annual rainfall amount is $1070 \mathrm{~mm}$, only equivalent to $42.8 \%$ of the rainfall received in the Shihmen reservoir watershed.

Table 1. Comparison of watersheds in Taiwan and Thailand.

\begin{tabular}{|c|c|c|}
\hline & $\begin{array}{c}\text { Shihmen reservoir } \\
\text { watershed }\end{array}$ & $\begin{array}{c}\text { Lam Phra Ploeng } \\
\text { basin }\end{array}$ \\
\hline $\begin{array}{c}24^{\circ} 25^{\prime} 45^{\prime \prime}- \\
\text { Latitude and }\end{array}$ & $\begin{array}{c}24^{\circ} 51^{\prime} 20^{\prime \prime} 18^{\prime} 30^{\prime \prime}- \\
121^{\circ} 10^{\prime} 15^{\prime \prime}- \\
121^{\circ} 23^{\prime} 10^{\prime \prime} \mathrm{E}\end{array}$ & $\begin{array}{c}14^{\circ} 38^{\prime} 30^{\prime \prime} \mathrm{N} \\
101^{\circ} 30^{\prime} 00^{\prime \prime}- \\
101^{\circ} 54^{\prime} 00^{\prime \prime} \mathrm{E}\end{array}$ \\
\hline Area of watershed & $75953 \mathrm{ha}$ & $81745 \mathrm{ha}$ \\
\hline River system & Dahan River & $\begin{array}{c}\text { Mekong River - } \\
\text { Lam Phra Ploeng } \\
\text { River }\end{array}$ \\
\hline $\begin{array}{c}\text { Reservoir capacity } \\
\text { Annual average } \\
\text { temperature }\end{array}$ & $207,000,000 \mathrm{~m}^{3}$ & $155,000,000 \mathrm{~m}^{3}$ \\
\hline Annual rainfall & $2500 \mathrm{~mm}$ & $1070 \mathrm{~mm}$ \\
\hline $\begin{array}{c}\text { Land use type } \\
\text { area }\end{array}$ & $\begin{array}{c}\text { Mostly protected } \\
\text { area }\end{array}$ & Mostly farmland \\
\hline Elevation & $220-3527 \mathrm{~m}$ & $256-1332 \mathrm{~m}$ \\
\hline $\begin{array}{c}\text { UTM coordinate } \\
\text { system }\end{array}$ & $\mathrm{UTM} 51 \mathrm{~N}$ & $\mathrm{UTM} 47 \mathrm{~N}$ \\
\hline $\begin{array}{c}\text { Year of } \\
\text { construction }\end{array}$ & 1956 & 1963 \\
\hline
\end{tabular}

\footnotetext{
* Corresponding author: waltchen@ntut.edu.tw
} 
To compare the soil erosion in the watersheds of Taiwan and Thailand, the Universal Soil Loss Equation (USLE) is used. It "is an erosion model designed to compute longtime average soil losses from sheet and rill erosion" [3]. The equation is (in metric units):

$$
A_{m}=R_{m} \times K_{m} \times \mathrm{L} \times \mathrm{S} \times \mathrm{C} \times \mathrm{P}
$$

$\mathrm{A}_{\mathrm{m}}=$ computed soil loss per unit area $(\mathrm{t} / \mathrm{ha} / \mathrm{year})$

$\mathrm{R}_{\mathrm{m}}=$ rainfall and runoff factor $(\mathrm{MJ}-\mathrm{mm} / \mathrm{ha} / \mathrm{hr} /$ year $)$

$\mathrm{K}_{\mathrm{m}}=$ soil erodibility factor $(\mathrm{t}-\mathrm{hr} / \mathrm{MJ} / \mathrm{mm})$

$\mathrm{L}=$ slope-length factor

$\mathrm{S}=$ slope-steepness factor

$\mathrm{C}=$ cover and management factor

$\mathrm{P}=$ support practice factor

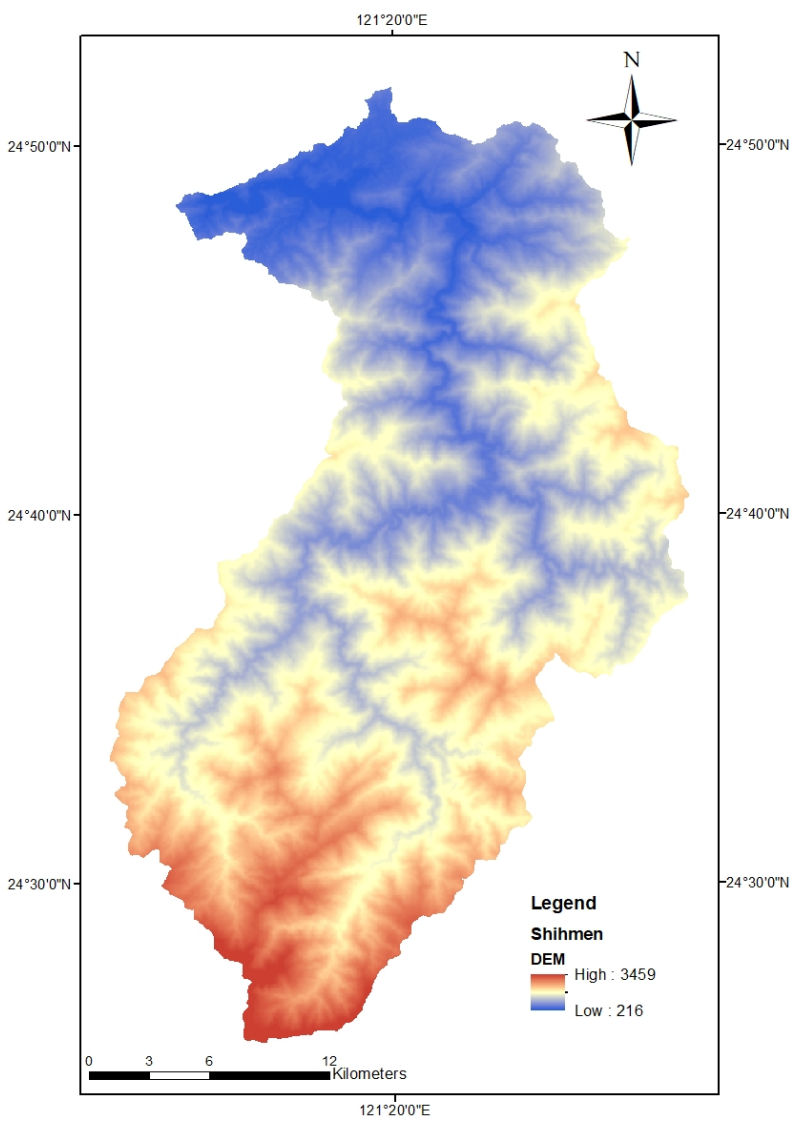

Fig. 1. Topographic map of the Shihmen reservoir watershed of Taiwan.

Due to the lack of concurrent data, erosion factors of different time periods are assumed to be representative of the study areas and used in this study. In order to apply Equation $1, \mathrm{Rm}$ is calculated from readings of rainfall stations (Thailand) or obtained from $\mathrm{Lu}$ et al. (2005; Taiwan [4]). $\mathrm{Km}$ is referenced from the land use data issued by the Thai government (Thailand) or obtained from Wann and Hwang (1989; Taiwan [5]). Both the L and $\mathrm{S}$ factors are computed from the Global Digital Elevation Model (GDEM) produced by the Advanced Spaceborne Thermal Emission and Reflection Radiometer (ASTER), which was released in 2011 (version 2). The $\mathrm{C}$ factor of Thailand is obtained from the land use data issued by the Thai government, and the $\mathrm{C}$ factor of Taiwan is derived from the correlation table between the land use data and the $\mathrm{C}$ factor [6]. Finally, the $\mathrm{P}$ factor is assumed to be one for both study areas.

The topographic maps of the Shihmen reservoir watershed and the Lam Phra Ploeng basin are shown in Fig. 1 and Fig. 2. The Shihmen reservoir watershed is long in the north-south direction and narrow in the eastwest direction, whereas the Lam Phra Ploeng basin is equally-sized in all directions. The analysis system is based on ArcGIS [7-9].

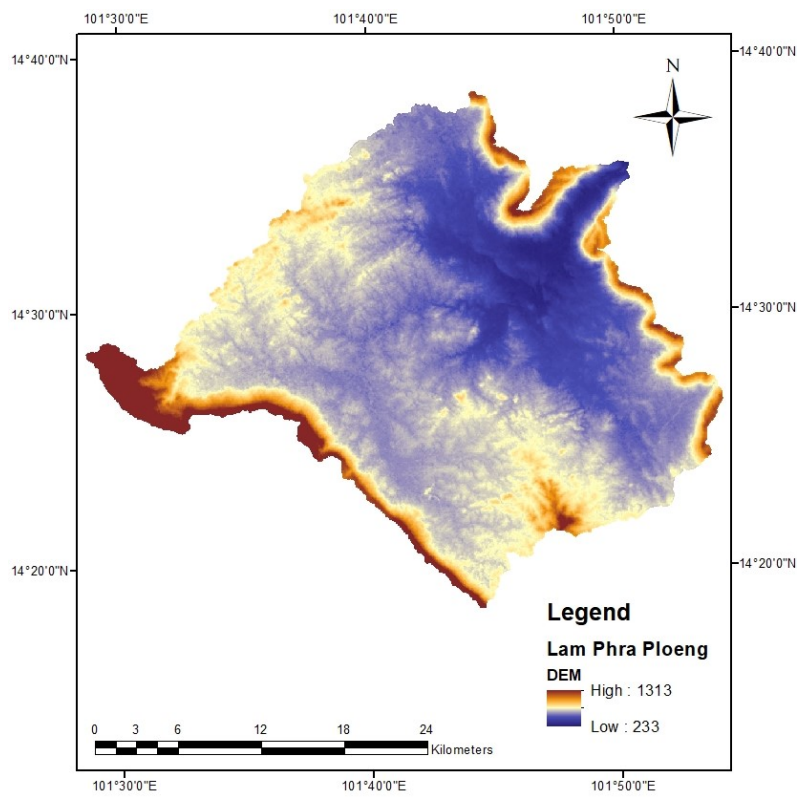

Fig. 2. Topographic map of the Lam Phra Ploeng basin of Thailand.

\section{Results}

The results of erosion factors computed from USLE are summarized in Table 2. As noted before, the Shihmen reservoir watershed has more than twice as much of rainfall as the Lam Phra Ploeng basin. This is reflected in the big difference of the $\mathrm{R}_{\mathrm{m}}$ factor (which also depends on rainfall patterns). Because of the sharp terrain, the Shihmen reservoir watershed also has a higher S factor than the Lam Phra Ploeng basin (18.291 vs. 3.925). In contrast, the Lam Phra Ploeng basin has a much higher C factor than the Shihmen reservoir watershed due to its agricultural use of the basin. The soil of the Lam Phra Ploeng basin is also more erodible than the Shihmen reservoir watershed (perhaps due to cultivation). The average $\mathrm{K}_{\mathrm{m}}$ factors are 0.261 (Lam Phra Ploeng basin) vs. 0.022 (Shihmen reservoir watershed).

Table 2. Comparison of soil erosion and erosion factors.

\begin{tabular}{|c|c|c|c|}
\hline & & $\begin{array}{c}\text { Shihmen reservoir } \\
\text { watershed }\end{array}$ & $\begin{array}{c}\text { Lam Phra Ploeng } \\
\text { basin }\end{array}$ \\
\hline \multirow{4}{*}{$\begin{array}{c}\text { Soil erosion } \\
\text { t/ha/yr }\end{array}$} & Max & 11922.59 & 1816.65 \\
\cline { 2 - 4 } & Min & 0.00 & 0.00 \\
\cline { 2 - 4 } & Mean & 68.03 & 67.57 \\
\cline { 2 - 4 } & Std & 210.01 & 115.33 \\
\hline
\end{tabular}




\begin{tabular}{|c|c|c|c|}
\hline \multirow{4}{*}{$\underset{\mathrm{t}-\mathrm{hr} / \mathrm{MJ} / \mathrm{mm}}{\mathrm{K}_{\mathrm{m}}}$} & $\operatorname{Max}$ & 0.042 & 0.300 \\
\hline & Min & 0.004 & 0.000 \\
\hline & Mean & 0.022 & 0.261 \\
\hline & Std & 0.006 & 0.044 \\
\hline \multirow{4}{*}{$\begin{array}{c}\mathrm{R}_{\mathrm{m}} \\
\mathrm{MJ}- \\
\mathrm{mm} / \mathrm{ha} / \mathrm{hr} / \mathrm{yr}\end{array}$} & Max & 15672.11 & 669.80 \\
\hline & Min & 9897.87 & 484.56 \\
\hline & Mean & 12797.92 & 547.19 \\
\hline & Std & 998.47 & 26.07 \\
\hline \multirow{4}{*}{$\mathrm{L}$} & Max & 1.415 & 1.291 \\
\hline & Min & 0.672 & 0.672 \\
\hline & Mean & 0.795 & 0.725 \\
\hline & Std & 0.082 & 0.076 \\
\hline \multirow{4}{*}{ S } & Max & 63.748 & 60.753 \\
\hline & Min & 0.065 & 0.065 \\
\hline & Mean & 18.291 & 3.925 \\
\hline & Std & 10.222 & 5.582 \\
\hline \multirow{4}{*}{ C } & Max & 1.000 & 0.600 \\
\hline & Min & 0.000 & 0.000 \\
\hline & Mean & 0.016 & 0.245 \\
\hline & Std & 0.043 & 0.241 \\
\hline
\end{tabular}

\section{Discussion and conclusions}

Using erosion classes defined in Thailand, the maps of erosion classes of the Shihmen reservoir watershed and the Lam Phra Ploeng basin are shown in Fig. 3 and Fig. 4, respectively. Distinct patterns emerge from both figures. For the Shihmen reservoir watershed, high erosion classes exist mostly in the mountain range. However, for the Lam Phra Ploeng basin, high erosion classes are everywhere in the bottom of the basin. Interestingly, the erosion factors cancel each other out over the study areas. The end result is that both watersheds have very similar amounts of soil erosion, which are $68.03 \mathrm{t} / \mathrm{ha} / \mathrm{yr}$ (Shihmen) and 67.57 t/ha/yr (Lam Phra Ploeng), respectively. The results suggest that the difference in soil erosion factors between the two watersheds can be quantified and is significant. They also suggest that more studies are required to elucidate these interesting findings.

This study was partially supported by the National Taipei University of Technology-King Mongkut's Institute of Technology Ladkrabang Joint Research Program (grant number NTUT-KMITL-106-01 and NTUT-KMITL-107-02) and the Ministry of Science and Technology (Taiwan) Research Project (grant number MOST 106-2119-M-027-004).

\section{References}

1. Y.-H. Liu, K. A. Nguyen, W. Chen, J. Wattanasetpong, U. Seeboonruang, Comparison of soil erosion between watersheds of Taiwan and
Thailand. In: International Symposium on Remote Sensing 2018, Pyeongchang, Korea (2018)

2. Northern Region Water Resources Office, About Shihmen Reservoir, Retrieved March 25, 2018, from http:/www.wranb.gov.tw/ct.asp?xItem $=928 \& \mathrm{CtNo}$ $\mathrm{de}=424 \& \mathrm{mp}=4$ (2017; in Chinese)

3. W. H. Wischmeier, D. D. Smith, Predicting rainfall erosion losses - a guide to conservation planning. U.S. Department of Agriculture, Agriculture Handbook No. 537 (1978)

4. J.-Y. Lu, C.-C. Su, I.-Y. Wu, Revision of the isoerodent map for the Taiwan area. Journal of Chinese Soil and Water Conservation, 36(2), pp. 159172 (2005; in Chinese)

5. S. S. Wann, J. I. Hwang, Soil erosion on hillslopes of Taiwan. Journal of Chinese Soil and Water Conservation, 20(2), pp. 17-45 (1989; in Chinese)

6. C. C. Wu, K.-F. Lo, L.-L. Lin, Handbook of soil loss estimation. National Pingtung University of Science and Technology (1996; in Chinese)

7. Y.-K. Jhan, Analysis of soil erosion of Shihmen reservoir watershed. Dissertation, National Taipei University of Technology (2014; in Chinese)

8. K.-J. Yang, Terrain factor analysis of soil erosion in Shihmen reservoir watershed. Dissertation, National Taipei University of Technology (2016; in Chinese)

9. D.-H. Li, Analyzing soil erosion of Shihmen reservoir watershed using slope units. Dissertation, National Taipei University of Technology (2017; in Chinese)

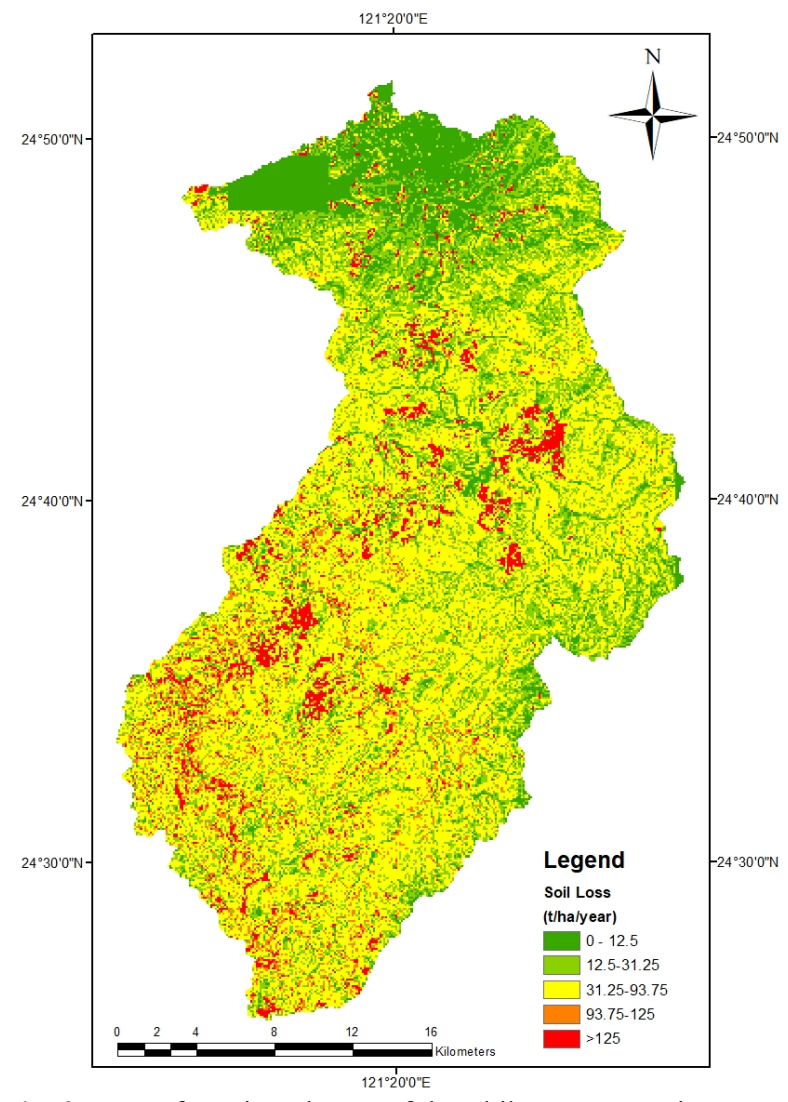

Fig. 3. Map of erosion classes of the Shihmen reservoir watershed. 


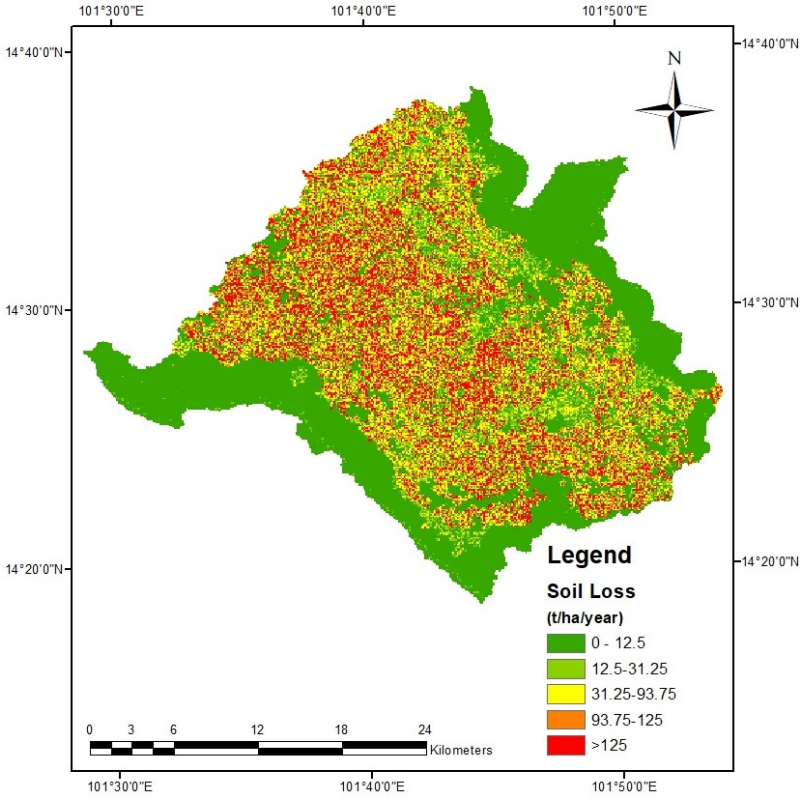

Fig. 4. Map of erosion classes of the Lam Phra Ploeng basin. 